\title{
'SEGUINDO!' MARKETING DIGITAL, INSTAGRAM E CONSUMO
}

'FOLLOWING YOU!' DIGITAL MARKETING, INSTAGRAM, AND CONSUMPTION

Recebido em 18.04.2020 Aprovado em 27.07.2020

Avaliado pelo sistema double blind revien

DOI: https://doi.org/10.32888/cge.v8i2.42263

\author{
Sabrina Maria Barbosa Quintiliano e Silva \\ quintilianosabrina@gmail.com \\ Universidade de Pernambuco - Caruaru/Pernambuco, Brasil \\ http://orcid.org/0000-0001-5075-4861

\section{Adriana Tenório Cordeiro} \\ adriana.cordeiro@upe.br \\ Universidade de Pernambuco - Caruaru/Pernambuco, Brasil \\ http://orcid.org/0000-0002-4046-4403
}

\section{Resumo}

Este estudo investiga o uso do Instagram como ferramenta mercadológica. Foi realizado survey online no perfil de uma empresa do ramo da moda para avaliar a percepção de 772 usuários acerca da influência desse perfil sobre suas decisões de compra. O Instagram como ferramenta do marketing digital exerce forte influência sobre a decisão de compra dos usuários, que são estimulados a consumirem produtos divulgados nas postagens, buscar produtos e seguir perfis para se atualizarem sobre produtos. Os resultados reafirmam a importância da presença ativa no ambiente digital para que empresas e marcas sejam vistas e lembradas.

Palavras-chave: Instagram. Marketing digital. Decisão de compra.

\begin{abstract}
This study investigates or uses Instagram as a marketing tool. An online survey was carried out on the profile of a fashion company to assess the perception of 772 users about the impact of this profile on their purchasing decisions. Instagram as a digital marketing tool has a strong influence on the purchase decision of users, who are encouraged to consume products posted on posts, search for products and follow tracking to update on products. The results reaffirm the importance of active presence in the digital environment for companies and brands, to be seen and remembered.
\end{abstract}

Keywords: Instagram. Digital Marketing. Purchase option. 


\section{Introdução}

Brasileiros estão cada vez mais conectados. Pesquisa feita no final de 2017 pelo IBOPE Conecta (Instituto Brasileiro de Opinião Pública e Estatística), junto a dois mil respondentes revelava que 75\% dos entrevistados usavam aplicativos de redes sociais, tais como o Whatsapp (91\%), Facebook (86\%) e Instagram (60\%) (IBOPE, 2017). Em levantamento feito pelo Comitê Gestor da Internet no Brasil em 2018, identificou-se que os internautas brasileiros chegavam a passar em média 9 horas e 14 minutos por dia conectados à internet. Em 2019, pesquisa feita da eMarketer identificou que 60,1 milhões de brasileiros são usuários do Instagram, atrás apenas dos Estados Unidos e Índia, com 106,7 e 62,1 milhões de usuários, respectivamente.

Estes são apenas alguns dados que realçam um campo de oportunidades para empresas no meio digital, tanto com páginas e conteúdos próprios, como também aparecendo em redes sociais de influenciadores digitais. Plataformas como o Instagram proporcionam às empresas valiosas interações com consumidores, aumentando o valor das marcas em relação a sua aplicação ao marketing. Estas plataformas facilitam e aceleram o processo de comunicação entre marcas e consumidores e podem se revelar decisivas para o sucesso das marcas (SANTOS, 2016). Na plataforma Instagram, em especial, em 2019 eram publicados diariamente cerca de 95 milhões de fotos e vídeos, registravam-se 4,2 bilhões de curtidas, com 67\% dos usuários na faixa etária de 18 a 34 anos (SEBRAE, 2019).

Atualmente, face a um cenário desafiador ligado à pandemia do novo Coronavírus, o uso do Instagram ampliou-se significativamente. Quando se consideram as categorias tanto no crescimento no volume de ações e conteúdo e ações por post, isoladamente, Governo e Saúde que se destacam. Contudo, à medida que a crise se amplia, os consumidores estão fazendo mudanças na maneira como interagem com o conteúdo nas redes sociais, e as empresas estão atentas à relevância do engajamento com a audiência. Um dos posts com maior engajamento recente tanto no Facebook quanto no Instagram, por exemplo, foi da Cervejaria Ambev que divulgou a ação da marca em transformar o álcool da cervejaria em álcool gel envasado nas próprias embalagens (CAMPOS, 2020).

Empresas também buscam influenciadores digitais, ou influencers, a quem pagam para que sua marca e produtos sejam divulgados em redes sociais. Influenciadores digitais são indivíduos que têm muitos seguidores e grande influência sobre seus adeptos. Também designados por Kumar e Gupta (2016) como formadores de opinião, os influenciadores reúnem seguidores e atuam como veículos para marcas, sendo que a opinião do influenciador transfere reconhecimento, confiança e respeito para um produto ou serviço anunciado. Até os políticos estão cada vez mais presentes em redes sociais, sendo que no período que antecedeu as eleições de 2018, por exemplo, 56\% dos brasileiros afirmaram que seu voto teria sido influenciado pelas redes sociais online (IBOPE, 2018).

O Instagram Business foi liberado no Brasil em agosto de 2016, um perfil especial para empresas, sendo que a diferença entre este e um perfil comum é que nele se tem acesso a quantidade de visitas no perfil, faixa etária, localização, gênero, interações, alcance, promoção de publicações, tempo que os seus seguidores passam por dia na plataforma, e o dia em que eles estão mais ativos. Essas são informações muito relevantes pois a partir delas é possível saber o que e quando publicar para seguidores. Entretanto, algumas empresas ainda não conseguem usar essas informações da melhor forma.

Um erro comum entre as empresas é o de acreditar que apenas criando um perfil, postando e/ ou fazendo parcerias com influencers, as empresas terão sucesso em vendas. As interações com os seguidores têm grande importância no alcance de novas contas, pois quanto mais curtido, comentado e compartilhado é um post, mais ele alcançará outras pessoas e mais fácil será conquistar novos seguidores e clientes potenciais. As parcerias são importantes, se usadas da maneira correta, pois se deve ter bastante cuidado com quem se contrata, por mais seguidores que um influencer tenha, o público alvo deste pode não ser o da empresa em questão, correndo-se o risco de perder o investimento, o qual por vezes pode ser bastante elevado.

Muitas empresas precisam se fazer presentes nas redes sociais, especialmente no Instagram, pois hoje este se tornou uma das ferramentas mais importantes, tanto para divulgação de marcas e produtos, como na aproximação com o cliente, seja por meio do perfil ou de um post patrocinado no perfil de um influenciador. E deve ser administrado com muita cautela, sendo que um feed mal organizado, desatualizado, com respostas grosseiras ou parcerias falhas pode manchar a imagem da empresa, com reflexo na perda de clientes.

ISSN 2318-9231

CGE | Rio de Janeiro | v. 8 | n. 2 | mai.-ago. 2020 
Este trabalho reconhece a importância de investigarmos o uso do Instagram enquanto ferramenta de marketing digital, em especial a partir da percepção dos clientes. Assim, o objetivo geral do trabalho consiste em avaliar a influência do marketing digital, praticado por empresas em seus perfis de Instagram, sobre o comportamento de consumo de clientes. Os objetivos específicos do trabalho incluem descrever o perfil de uso do Instagram por cliente de uma loja específica e identificar a percepção de clientes quanto à influência do perfil da loja no Instagram. Este artigo está estruturado em cinco seções, sendo que após a introdução se apresentam os fundamentos conceituais do estudo; na seção 3, são apontados os procedimentos metodológicos do trabalho, seguido de uma seção que discute seus resultados. Na seção 5 apontamos as principais conclusões do estudo, seguidas das referências do artigo.

\section{Marketing digital}

O êxito de uma empresa se dá pela em geral grande procura de seus produtos ou serviços, e consequentemente de um bom volume de vendas, sendo que o marketing desponta como responsável por este aumento, um elemento crucial ligado ao sucesso das empresas (KOTLER; KELLER, 2012). O marketing está voltado ao atendimento de necessidades e desejos dos consumidores, procurando conhecê-los para assim construir caminhos para sua satisfação. Este seria o centro de qualquer ação de marketing, isto é, a garantia de estratégias de sucesso e sempre acompanhando as mudanças de comportamento dos consumidores, inovando-se na ação mercadológica (CINTRA,2010).

O Marketing ainda é definido como uma atividade onde ocorre a elaboração, execução, preço, comunicação e distribuição de bens e serviços, criando trocas entre empresa e consumidor atendendo e satisfazendo objetivos individuais e organizacionais. O marketing tem, assim, a função de lidar com os clientes e seus objetivos principais incluem cultivar, manter os atuais clientes e atrair novos, proporcionando satisfação. Este processo é utilizado para que as empresas possam criar relacionamentos com os consumidores (KOTLER, 2007).

Podemos destacar que o marketing digital e o tradicional possuem uma mesma finalidade, isto é, a de alcançar o público-alvo determinado e manter um bom relacionamento com os clientes, garantindo que a empresa seja sempre lembrada. Além disso, os dois precisam de um plano que estabeleça estratégias para desenvolver práticas que estreitem o relacionamento com os clientes, com ações de diálogo digital, fortalecendo a imagem da empresa na internet, e ampliando os negócios (CINTRA, 2010).

Mas a força do marketing digital nas empresas está diretamente atrelada às mídias sociais online, já que possuem ferramentas que permitem a interação e compartilhamento de conteúdo com os consumidores, invertendo o vetor do marketing, que seguia da empresa para o consumidor e agora segue também do cliente para a empresa e entre clientes (GABRIEL, 2010).

O nível de proximidade da organização com os consumidores facilita sua integração ao negócio, permitindo que estes participem continuamente na construção e desenvolvimento da empresa. Por meio da internet, o cliente pode manter contato frequente e dinâmico com a empresa, revelando assim ideias e opiniões acerca de seus interesses em torno do produto, sugerindo melhorias ou até mesmo novos produtos (CHAFFEY; SMITH, 2008, apud SANTOS, 2016).

A perspectiva de não se investir em marketing digital, além de restringir a comunicação com os clientes, abre portas para comentários negativos sobre a empresa ou marca, sem que a empresa tenha conhecimento nem possibilidade de resposta, podendo gerar vários problemas, uma vez que os consumidores querem falar e serem ouvidos. Por um lado, não estar inserido na internet hoje afeta diretamente um negócio, pois no ambiente digital se encontram informações importantes sobre clientes e concorrentes. Por outro lado, para não se investir muitos recursos financeiros em publicidade aleatória na internet, é preciso ampliar o olhar, conhecer as plataformas digitais e em qual ou quais os consumidores estão presentes (TORRES, 2009).

Há autores, como Kotler e Keller (2012), que defendem que todas as decisões sobre o marketing devem ser tomadas em um ambiente fomentado pela internet, seja o projeto de um novo produto, precificação, onde vender, 
divulgar e o quanto gastar com marketing digital e propaganda. Maia et al. (2018) discutem a importância do marketing digital para fazer avançar a construção de vantagens competitivas nos negócios, edificar relacionamentos com clientes com otimização de recursos e o engajamento na internet com a perspectiva de parceria. As transformações do mercado e no perfil de consumidores elevam a importância do marketing digital para os negócios.

Assim, o marketing digital passou a ter uma importância ainda maior com o surgimento das redes sociais online. Em acréscimo, foi especialmente a partir destes canais comunicacionais virtuais que as empresas passaram a enxergar na Internet o papel de uma ferramenta de interação com clientes atuais e potenciais, além de uma fonte de negócios em geral. As redes sociais, e suas funcionalidades cada vez mais engajadoras, transformaram-se em canais ideais para o Marketing Digital, tanto para divulgação de marcas, como a venda de produtos ou serviços (FURLAN e MARINHO, [s.d.]). Discutimos esses aspectos no próximo tópico.

\section{Mídias sociais online}

As redes sociais reúnem pessoas que divulgam uma diversidade de dados e informações, e postam fotos, áudios, vídeos ao mesmo tempo em que interagem com outros usuários. A partilha de dados pode levar, por exemplo, à criação de novos conteúdos, recomendações ou compartilhamento de ideias, experiências e conhecimento, crítica a produtos, serviços ou marcas ou debates de temas atuais, interesses ou bobbies (RYAN; JONES, 2009). Atualmente as empresas conseguem estreitar seu relacionamento com os clientes a partir das redes sociais. A internet disponibiliza várias ferramentas para os usuários, mas as mídias sociais se destacam por possuir um grande poder de influência e terem se tornado parte do dia a dia dos usuários, sendo usada para diversos fins (OLIVEIRA, 2018).

As redes sociais são elementos importantes das campanhas de marketing na internet, oferecem vantagens competitivas sobre empresas que não estão ali presentes, e na relação com clientes. No ambiente digital das redes, as empresas podem divulgar produtos, serviços, marcas e até mesmo seu posicionamento diretamente para o seu público-alvo, minimizando falhas na comunicação, lançar campanhas promocionais interativas, comunicar-se diretamente com o consumidor em tempo real. Pode-se elevar, assim, números em vendas em âmbito virtual (FURLAN E MARINHO, [s.d]).

Segundo o estudo Social Media Trends de 2019, 96,2\% dos usuários de internet já faziam parte de alguma rede social, sendo as mais utilizadas Facebook e Instagram, que promovem maior engajamento. 62,6\% das empresas consideravam que as redes sociais têm papel muito importante e $42,1 \%$ já tinha mais de 3 anos de uso das redes sociais e citaram como principais benefícios a divulgação e o engajamento das marcas com seus clientes. O principal motivo de não estarem presentes seria a falta de uma equipe e tempo para o gerenciamento das redes (KANTAR MEDIA, 2019). Para 2020, a Kantar Media, em seu relatório Getting Media Right, aponta que o meio digital deve consolidar seu domínio, e indica que $84 \%$ dos profissionais de marketing pretendem aumentar o investimento com vídeos online, ao passo que 70\% deve aumentar os investimentos nas redes sociais (FARIAS, 2019).

O marketing em redes sociais possui várias vantagens, entre elas o baixo custo com investimento e manutenção, resultados obtidos em curto prazo, disponibilização de ferramentas que auxiliam na divulgação da informação e controle dessas informações (SILVA, 2017). As empresas, que veem as redes sociais como meio importante na comunicação com seus consumidores esperam que o conteúdo compartilhado transcenda o meio virtual e gere ações de compra ou a expressão de opiniões sobre a empresa. Para isso, é necessário que haja conscientização dos envolvidos e mobilização de recursos organizacionais, isto é, objetivo e estratégia empresarial (DIZARD, 2000).

Assim, as redes têm sido ferramenta relevante na atração de novos clientes, pois é possível obter feedback logo após a publicação de determinado produto, o que permite à empresa ter ideia de como o produto anunciado é aceito pelo público, podendo até orientá-lo no caso de feedback negativo, como no caso de produtos defeituosos, de maneira que se tenha uma resposta rápida e visível a outros consumidores que venham a ter o mesmo problema. Além de serem grandes aliadas na comunicação com os clientes, que buscam nas redes praticidade e informações de qualidade de forma rápida, as redes também são usadas pelas empresas como forma de se posicionarem 
estrategicamente diante de seus consumidores, da forma como querem ser vistos e reconhecidos no mercado (COHEN, 2018).

\section{Instagram como ferramenta mercadológica}

O Instagram foi criado por Kevin Systrom e pelo brasileiro Mike Krieger em 2010. Apenas um ano após seu lançamento, já contava com dez milhões de usuários, mesmo estando disponível apenas para iPhones e iPads. Em 2012, o aplicativo se tornou disponível para todos os celulares com sistema Android e foi comprado pelo Facebook no mesmo ano, por cerca de um bilhão de dólares. Hoje o Brasil é o terceiro maior público, com mais de 60 milhões de usuários (KANTAR MEDIA, 2019; ROCK CONTENT, 2019). Esta plataforma permite o compartilhamento instantâneo de fotos e vídeos, sendo que as pessoas podem interagir, comentando e curtindo as postagens. Há dois tipos de perfis para uso pessoal, um que pode ser 'aberto', permitindo que qualquer indivíduo siga outro e acompanhe as suas postagens, ou outro 'privado', onde apenas os seguidores autorizados podem ver as publicações.

Existem outras ferramentas disponíveis, como a de explorar, onde se busca por perfis e hashtags, e onde também aparecem sugestões de posts relacionados às postagens e perfis com que mais se interage; o direct funciona como um chat privado, que também permite a criação de grupos, sendo que a mais utilizada é o Instagram stories, onde é possível fazer transmissões ao vivo, postar vídeos e fotos, que aparecem por 15 segundos ou menos e somem após $24 \mathrm{hrs}$. Também é permitido adicionar filtros, gifs, stickers, hora, temperatura, música, votações, caixa de perguntas, mencionar perfis, entre outras possibilidades. O usuário consegue acompanhar quem e quantas pessoas curtiram sua postagem ou visualizaram o seu stories. Há pouco tempo a quantidade de curtidas poderia ser vista por qualquer seguidor, mas como forma de acabar com o clima de competição entre os usuários, esta ação foi retirada como estratégia de tornar a rede social mais saudável.

Visando as empresas, o Instagram criou um perfil especial, o Instagram business que permite as mesmas ações que um perfil pessoal, mas possui ferramentas extras; nessa modalidade de perfil, é possível patrocinar posts para que apareçam para possíveis clientes potenciais, também se tem acesso a informações extras, como quantidade de visitas semanais ao perfil, faixa etária dos seguidores, gênero, cidade, horários e dias que eles estão mais ativos, quantidades de interações e visualizações dos posts.

Esse tipo de perfil não é usado apenas por empresas, mas também pelos digital influencers, também conhecidos como criadores de conteúdo dos mais diversos tipos - humor, literatura, moda, beleza, politica, noticias, fofocas, dia a dia, culinária, maternidade, entre outros assuntos - e chegam a possuir milhões de seguidores. Pelo grande poder de influência sobre seus seguidores, muitos fazem parcerias pagas com algumas marcas para divulgá-las em seu perfil.

Ao revelar o poder de influência dos formadores de opinião individuais, Almeida et al. (2018) conduziram um estudo cujos resultados refletem a necessidade que indivíduos seguidores têm de criar experiências com outros indivíduos, os formadores de opinião individuais, enquanto criam e consomem conteúdos gerados online. O estudo explora a dinâmica de funcionamento do engajamento nas redes sociais virtuais, fundamentada em formadores de opinião (individuais), que produzem vínculos positivos com seus públicos por meio da publicação de conteúdo. De forma prática, os autores esclarecem o uso de influenciadores digitais como um caminho para empresas e marcas investirem como uma alternativa em seu mix promocional.

Pesquisa feita por Jacinto (2017) em Lisboa (Portugal) revelou que 79\% das pessoas entrevistadas, com idade entre 22 e 26 anos, em sua maioria mulheres, costumam usar o Instagram todos os dias. Seu estudo revelou que é a interação social que promove o envolvimento dos usuários com os perfis das marcas por meio da troca de conteúdos entre consumidores. Outro estudo, de Aragão et al. (2016), indica que o marketing boca a boca está muito presente no Instagram, sendo que dos $47,3 \%$ de usuários entrevistados, que marcam seus amigos em publicações, 45,6\% afirmam que também recebem marcações em postagens que são de seu interesse. 
Macêdo (2016), por sua vez, observou que as adolescentes possuem uma relação especial com produtos relacionados a moda e beleza, e utilizam o Instagram como fonte de conhecimento, de forma a acompanhar as novas tendências, e acabam seguindo diversas influenciadoras digitais. A autora afirma que o Instagram pode ser considerado, atualmente, o principal meio de informação sobre moda.

No contexto da moda ainda, o estudo de Santos (2016), que usou o perfil da marca Levi's como objeto de estudo, constatou que a partir das imagens, das publicações da marca no Instagram, apresentadas, influenciaram a atitude da maioria dos entrevistados. A autora aponta que a visita ao perfil da Levi's no Instagram pode influenciar positivamente a atitude dos consumidores relativamente à marca. A seguir serão apresentados os procedimentos metodológicos adotados nesse estudo.

\section{Procedimentos metodológicos}

Quanto aos objetivos de pesquisa, este estudo é exploratório. Optou-se por uma abordagem exploratória com a intenção de coletar dados relevantes e de opinião de partes interessadas, como explica Gil (2008) "pesquisas exploratórias são desenvolvidas com o objetivo de proporcionar visão geral, de tipo aproximativo, acerca de determinado fato". Foi realizada uma pesquisa a partir da abordagem de estudo de caso (YIN, 2001), sendo que a unidade de análise é uma loja multimarcas de maquiagem, tanto para uso pessoal ou profissional e também vende produtos de cuidados pessoais; possui loja física na cidade de Surubim-PE, mas envia seus produtos para todo Brasil.

A loja Chloe, que consentiu com a realização deste estudo e divulgação de seu nome, foi inaugurada em 2016 e desde então, usa o Instagram como ferramenta de divulgação de seus produtos. É muito popular na cidade e na plataforma conta com mais de 12 mil seguidores; em 2017 lançou sua própria marca de maquiagens, Chloe Make Up, e em novembro de 2019 lançou uma nova marca voltada para profissionais chamada Vaske.

Para a pesquisa, foi realizado um levantamento (survey) junto aos seguidores do perfil a partir de formulário eletrônico disponibilizado em novembro de 2019, no perfil do Instagram da loja. O questionário visava identificar a influência das postagens nas vendas da loja física, e foi criado a partir do Google Forms, sendo composto por 27 perguntas, e dividido em duas partes: a primeira com 14 perguntas acerca do perfil de uso do Instagram, e a segunda parte, com 13 perguntas específicas sobre o perfil da loja Chloe. A amostra foi de 772 indivíduos.

Dos 772 respondentes, $51,2 \%$ estão na faixa etária de 18 a 24 anos, 21,1\% de 25 a 32 anos; estes, segundo informações do próprio Instagram, estão na faixa etária da maioria dos usuários, que varia de 18 a 34 anos. Os demais possuem menos de 18 anos (19,2\%), 33 a 40 anos (6,7\%), 41 a 47 anos (1,6\%) e 0,3\% possuem 48 anos ou mais. 92,9\% são residentes no Estado de Pernambuco e demais Estados somam 7,1\% (Paraíba, São Paulo, Alagoas, Bahia, Goiás, Maranhão, Minas Gerais e Rio Grande do Sul). Os dados foram analisados a partir de análises estatísticas univariadas e distribuição de frequências. Na seção a seguir, apresentamos os resultados do estudo.

\section{Apresentação e análise dos resultados}

Para apresentação e discussão dos resultados do estudo, consideramos inicialmente a descrição do perfil dos usuários participantes da pesquisa, para em seguida discutirmos a percepção dos respondentes quanto à influência do perfil da loja Chloe sobre suas decisões de compra.

\section{Usuários do Instagram: perfil de uso}

Dos 772 respondentes, mais de $99,3 \%$ afirmam usar a rede social todos os dias, seja uma, algumas ou várias vezes e 65,2\% afirmam não ter um horário específico de uso, 26,7\% costumam usar a noite, 5,6\% à tarde e 2,5 na parte da manhã. Sobre a finalidade do uso do Instagram, 572 pessoas afirmam que usam o Instagram como forma de entretenimento e para acompanhar novidades e notícias e 357 para interagir com os amigos. 
Como destacado anteriormente, o Instagram deixou de ser apenas uma rede social, em que se posta fotos e interage com os amigos, passou a ser também um meio de divulgação de marcas, vendas produtos e estreitamento do relacionamento com o consumidor, como afirma Gabriel (2010). Esse aspecto foi observado nesta pesquisa, sendo que 249 pessoas afirmam usar o Instagram para fazer compras e 198 usam como ferramenta de trabalho.

Na pesquisa realizada, 99,8\% dos respondentes seguem perfis de lojas no Instagram, 93,1\% usam a rede social para pesquisar sobre o produto que pretendem comprar. As empresas que estão presentes na plataforma esperam que o conteúdo se converta em compras, mas as empresas que não estão presentes no Instagram perdem a oportunidade de aparecer nessas pesquisas e acabam não se tornando uma opção de compra para os consumidores.

Gráfico 1- Influência de compra de produtos vistos no Instagram

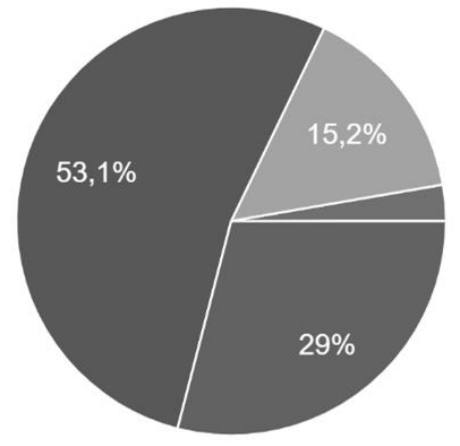

Extremamente influenciado

Muito Influenciado

Pouco influenciado

Não me sinto influenciado

Fonte: Elaborado pelas autoras

Identificou-se que $97,3 \%$ dos respondentes se sentem de alguma forma influenciados a comprar produtos expostos no Instagram (Gráfico 1), seja extremamente $(29 \%)$, muito $(53,1 \%)$ ou pouco $(15,2 \%)$. As publicações influenciam bastante os consumidores, que acabam por optar por um determinado produto na hora da compra, já que $93,8 \%$ assume ter comprado algum produto visto no Instagram. Como afirmam Furlan e Marinho ([s.d.]), as redes sociais são canais ideais para o marketing digital, tanto para divulgação de marcas, como venda de produtos ou serviços.

Silva (2017) afirma ainda que resultados do uso das redes sociais podem ser obtidos em curto prazo. Como vemos na presente pesquisa, 93,8\% dos respondentes afirmam ter comprado algum produto visto no Instagram, sendo que $34,7 \%$ haviam realizado a compra ainda no mês de novembro, quando o questionário estava sendo aplicado, e 553 alegaram ter tomado conhecimento do objeto por postagens da própria marca.

As redes sociais possuem um grande poder de influenciar os consumidores, por isto o seu uso tem uma importância significativa para a atuação das empresas, sobretudo em cenários hipercompetitivos (OLIVEIRA, 2018). A empresa que não está presente no Instagram, seja ela de grande ou pequeno porte, acaba se excluindo de um mercado digital em franca expansão, sendo que apenas no Brasil são mais de 60 milhões de usuários, conforme destacado em seção prévia; além disso, trata-se de um meio de divulgação simples, de baixo custo e que tende a dar retorno se usado de forma efetiva.

\section{Seguidores de perfil: percepções acerca da influência da loja no Instagram}

Nesta seção, discutimos a percepção dos respondentes quanto à influência do perfil da loja Chloe sobre suas decisões de compra. Mais de $40 \%$ dos seguidores do perfil tomaram conhecimento da loja a partir do próprio Instagram da marca. Os seguidores da Chloe costumam acompanhar as novidades da loja no Instagram, sendo que 745 acompanham através do Instagram stories, ferramenta bastante usada pelo perfil, e geralmente alimentada todos os dias. 
Como a loja possui uma marca própria, foi indagado aos respondentes se os seguidores têm conhecimento da mesma. Observou-se que 89,9\% conhecem a marca e 50,5\% utilizaram algum produto. Conforme Gráfico 2, observa-se que $99,1 \%$ dos respondentes se sentem de alguma forma influenciados a comprar, seja extremamente $(45,9 \%)$, muito $(47,1 \%)$ ou pouco $(6,1 \%)$. As postagens do Instagram despertam no consumidor o desejo de obter aquele produto, mesmo que antes ele não tivesse conhecimento sobre ele, além da imagem a descrição dos produtos nas postagens ajuda no reconhecimento dessa necessidade. A plataforma também permite o uso de vídeos, que podem ser por exemplo a demonstração de um produto, o que pode contribuir para convencer ainda mais o consumidor a comprar, sendo que isso é permitido até em uma única postagem.

Gráfico 2: Influência de compra de produtos vistos no perfil da loja Chloe

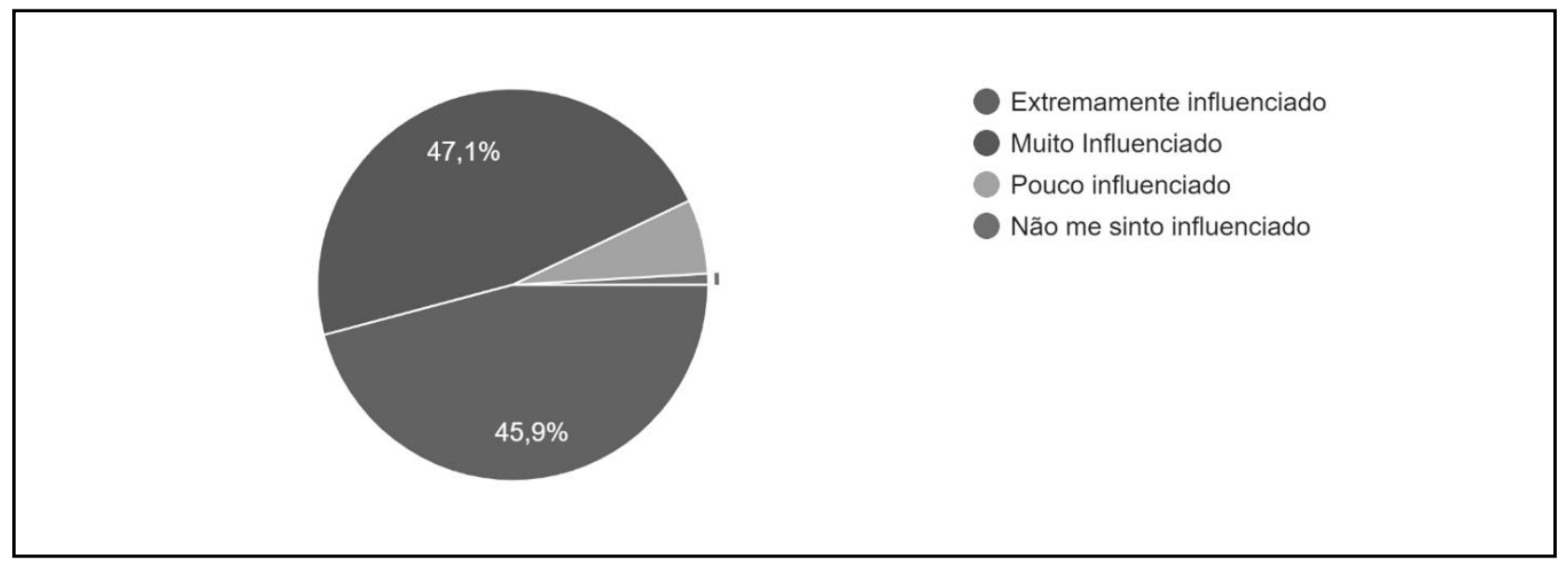

Fonte: Elaborado pelas autoras

Dos indivíduos que se sentem influenciados, $83,1 \%$ já realizaram compras na Chloe, o que reforça a ideia do poder que as postagens exercem sobre as pessoas que as acessam. Destaca-se que 43,2\% dessas compras havia sido nos 6 meses anteriores à aplicação do questionário, 32,2\% no mês de novembro de 2019 (quando foi realizado o levantamento), 13,4\% em 2019, 8,8\% na semana de aplicação do questionário, e 2,4\% ano anterior (2018), mostrando-se que o retorno em compras do uso contínuo do Instagram é rápido.

O uso das redes sociais para divulgação dos produtos tende a repercutir em termos de aumento de vendas. No caso estudado, $64,5 \%$ dos respondentes tomaram conhecimento dos produtos comprados através do próprio perfil da loja (Gráfico 3), que é alimentado todos os dias, principalmente o Instagram stories que é a ferramenta mais utilizada para as postagens do perfil e a que os seguidores mais utilizam para acompanhar as novidades.

Gráfico 3: Tomada de conhecimento do produto

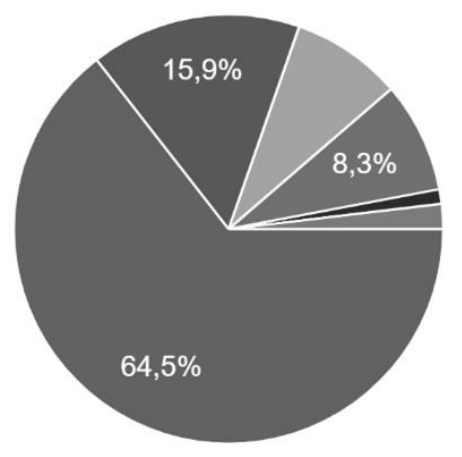

Instagram da Loja Chole

Loja física

Indicação de amiga

Indicação de blogueira

Indicação de familiar

Pesquisa na internet

Fonte: Elaborado pelas autoras 
Assim, observa-se a importância da empresa manter seu perfil atualizado na rede social, para que os seguidores possam acompanhar a chegada de novos produtos ou reposições de algum produto que desejam; um feed desatualizado pode deixar uma má impressão entre os seguidores, que estão sempre buscando por novidades; além disso, a marca pode cair no esquecimento e a empresa perder clientes. O marketing digital contribui para estreitar, assim, o relacionamento com os clientes, e um bom relacionamento fortalece a imagem da empresa na internet (CINTRA, 2010). Foram colocadas perguntas acerca do atendimento e de aspectos que a Chloe tem a melhorar. Sobre o atendimento no Instagram, 86,9\% dos respondentes o julgam como 'muito bom', 12,2\% como 'bom', e os demais como 'regular'.

Algo bastante comum no perfil da loja Chloe são as postagens do feedback dos seus clientes, o que acaba de certa forma aproximando a empresa dos seus clientes, pois eles acabam se sentindo mais especiais, além disso pode ser uma forma de outros consumidores tomarem conhecimento da loja, já que esses clientes sempre mencionam a empresas nas postagens. Em relação aos aspectos destacados como passíveis de melhoria, indagado a partir de pergunta aberta no questionário, 113 indivíduos responderam 'conteúdo do Instagram', ponto de grande relevância pois o perfil do Instagram atua como uma vitrine, então é preciso se atentar à qualidade das imagens ou vídeos publicados, atenção à linguagem usada e se manter sempre um feed organizado, pois uma vitrine bem trabalhada chama atenção do consumidor.

O principal aspecto a ser melhorado, a partir da perspectiva de 508 respondentes, seria o 'espaço da loja física'. A 'variedade de produtos' foi aspecto destacado por 108 respondentes, enquanto 39 citaram o 'atendimento no Instagram'. Por fim, 21 indivíduos citaram o 'atendimento na loja física' como passível de melhoria. A partir da criação, pela empresa, de um perfil numa rede social, é de extrema importância responder aos os clientes e saber se posicionar diante de situações embaraçosas, pois uma situação poderá ser exposta para toda a rede social, podendo prejudicar a imagem da empresa. A seguir, são destacadas as conclusões do estudo.

\section{Considerações finais}

Este trabalho buscou avaliar a influência do marketing digital, praticado por empresas em seus perfis de Instagram, sobre o comportamento de consumo de clientes. Em especial, buscou-se descrever o perfil de uso do Instagram por cliente de uma loja específica e identificar a percepção de clientes quanto à influência do perfil dessa loja no Instagram. Consideramos como fundamentos os aspectos conceituais ligados ao marketing digital, em especial em sua interface com as redes sociais online, e reconhecendo a relevância da ação mercadológica a partir do Instagram diante de um cenário hipercompetitivo.

A partir do estudo de caso junto à loja Chloe, e levantamento conduzido a 772 seguidores de seu perfil no Instagram, foi possível concluir que o uso do Instagram como ferramenta do marketing digital exerce grande influência sobre a decisão de compra dos consumidores, os quais são estimulados a comprarem produtos que foram vistos no Instagram. Os resultados obtidos reafirmam a importância da presença ativa de empresas no ambiente digital, em especial em plataformas digitais como o Instagram, para que elas e suas marcas sejam vistas e lembradas pelos consumidores em suas buscas. Afirma-se uma compreensão do Instagram que extrapola a ideia de uma simples rede social para se considerar uma plataforma de ação estratégica que contempla a divulgação de produtos, marcas e canal para se estreitar a relação com o cliente.

O estudo observou, ainda, que um perfil ativo no Instagram pode ter outras funções além da divulgação e venda de produtos e serviços, pode trazer informações como localização e funcionamento da loja física, quando houver, horário de funcionamento, link de sites, formas de pagamento, além de avisos, como por exemplo, no caso da loja estar ou não aberta em feriados.

A partir da percepção dos respondentes sobre aspectos passíveis de melhoria na empresa estudada, compreendese a relevância do bom atendimento também no âmbito da loja física, e também de estar sempre disponível para os consumidores, isto é, não deixar de responder comentários ou mensagens. É relevante ainda estar bem informado sobre os produtos para que se possa tirar dúvidas, pois um bom atendimento pode ser um diferencial, que leve o consumidor a escolher a empresa. 
A pesquisa realidade concluiu que o uso do Instagram traz impactos significativos sobre as vendas da empresa estudada. O estudo corrobora, ainda, a ideia de que o Instagram aproxima empresas e clientes, à medida que é cada vez mais parte do dia a dia de seus usuários, e consiste em meio simples e acessível para uma empresa alcançar o público.

O perfil da loja estudada é bastante ativo, com postagens diárias, foi possível observar que os seguidores têm uma proximidade com os donos do perfil, os quais gerenciam e sempre aparecem nos stories e transmissões ao vivo, mostrando novos produtos e fazendo demonstrações de uso. Também pedem a opinião de seus seguidores, a exemplo de sugestões para novos produtos para a loja. Mas por vezes cometem erros de português e usam uma linguagem bastante coloquial, o que pode prejudicar a percepção de uma postura mais profissional.

Outro problema identificado a partir do estudo do caso foi a falta de postagens no feed, pois não há postagens com tanta frequência como nos stories, que aparecem apenas por 24 horas e depois somem, o que pode fazer com que alguns seguidores não consigam vê-lo antes de sair do ar. Os mesmos produtos anunciados nos stories também poderiam ser anunciados no feed para que antigos e principalmente novos seguidores pudessem se atualizar sobre os novos produtos e reposições. Algo muito pedido pelos seguidores participantes desde estudo se referiu à ampliação da loja física, que é pequena para a quantidade de produtos que possui, o que acaba dificultando a visualização dos produtos pelos clientes, já que eles ficam muito próximos uns dos outros. Este problema poderia ser minimizado a partir de uma reorganização dos produtos, caso a mudança de local seja inviável.

O Instagram, em especial, possui diversas opções, tanto pagas (como a possibilidade de pagar para que uma postagem apareça para usuários que não seguem o perfil) como gratuitas (por exemplo, o horário de pico de uso do Instagram pelos seguidores do perfil, que facilitam a obtenção de informações, ajudando na divulgação e no crescimento das vendas). Além disso, é preciso atentar aos conteúdos postados, qualidade das fotos ou vídeos, sempre descrever o produto para melhor entendimento do consumidor, pois às vezes uma imagem ou vídeo não é suficiente. É preciso que a empresa seja cautelosa quanto a posicionamentos no Instagram, seja numa resposta a algum comentário, direct, ou postagem, pois eles podem ser mal interpretados e assim prejudicar a credibilidade da empresa, algo bastante difícil de reverter.

Considerando a importância do assunto, cabem pesquisas futuras para o aprofundamento quanto à relação entre conteúdos de imagens e vídeos publicados no Instagram e a escolha de consumidores por determinados produtos ou serviços, em especial para se avaliar mudanças em nível de engajamento a partir do meio (imagem única, composição de imagens, vídeos etc.) utilizado para veicular a mensagem da empresa.

Salienta-se, a partir da discussão do estudo de caso realizado, que o Instagram atua como ampla vitrine para empresas, além de ser considerado canal viável para relacionamento com os clientes. No cenário atual, hipercompetitivo e desafiado pelos efeitos da pandemia do novo Coronavírus sobre a economia, as medidas de isolamento social têm ampliado o uso de tecnologias da informação e comunicação, sendo que as redes sociais online demandam um olhar investigativo mais atento à medida que contribuem para moldar percepções de consumidores-usuários e repercutir em resultados organizacionais concretos.

\section{Referências}

ALMEIDA, M. I. S. de; COELHO, R. L. F.; CAMILO-JUNIOR, C.G.; GODOY, R. M. F. de. Quem Lidera sua Opinião? Influência dos Formadores de Opinião Digitais no Engajamento. Revista de Administração Contemporânea, Rio de Janeiro, v. 22, n. 1, art. 6, p. 115-137, jan/fev, 2018.

ARAGÃO, F; FARIAS, F; MOTA, M; FrEITAS, A. Curtiu, comentou, comprou. A Mídia Social Digital Instagram e o Consumo. Revista Ciências Administrativas, v. 22, n. 1, p. 130-161, 2016.

CAMPOS, N. Consumo das redes sociais no Brasil durante a pandemia de Coronavírus. Comscore. 24/03/2020. Disponível em: < https://www.comscore.com/por/Insights/Blog/Consumo-das-redes-sociais-noBrasil-durante-a-pandemia-de-Coronavirus > acesso em 18 abr 2020. 
CINTRA, F. Marketing Digital: a era da tecnologia on-line. Investigação, v. 10, n. 1, p. 6-12, 2010.

COHEN, G. M. Marketing Digital: O uso do Instagram na percepção de empresários na cidade de Campina Grande/PB. Trabalho de Conclusão de Curso (Graduação em Administração). Universidade Estadual da Paraíba, Campina Grande, 2018.

DIZARD JR., W. A Nova Mídia: A Comunicação de Massa na Era da informação. Rio de Janeiro: Jorge Zahar, 2000.

GABRIEL, M. Marketing na era Digital. São Paulo: Novatec, 2010.

FARIAS, T. Kantar revela tendências de mídia para 2020. 18/12/19. Disponível em: < https://www.meioemensagem.com.br/home/midia/2019/12/18/audio-streaming-e-e-commerce-em-alta-em2020.html Acesso em: 7 jan 2020.

FURLAN, B.; MARINHO, B. Redes sociais Corporativas. Instituto Desenvolve TI: cursos para capacitação digital. [s.d.]. Disponível em: <www.institutodesenvolveti.org.: Acesso em: 7 nov 2019.

IBOPE. 2017. WhatsApp é o app de rede social mais usado pelos internautas brasileiros. Disponível em: <http://www.ibopeinteligencia.com/noticias-e-pesquisas/whatsapp-e-o-app-de-rede-social-mais-usado-pelosinternautas-brasileiros $\_>$Acesso em 30 de agosto de 2019.

IBOPE. 2018. Redes sociais e mídias tradicionais são as fontes de informação com mais influência na escolha do presidente em 2018. Disponível em: <http://www.ibopeinteligencia.com/noticias-epesquisas/redes-sociais-e-midias-tradicionais-sao-as-fontes-de-informacao-com-mais-influencia-na-escolha-dopresidente-em-2018/> Acesso em 30 ago 2019.

JACINTO, F. Marketing de Conteúdo Integrado no Instagram: Um estudo sobre o Envolvimento da Geração Milénio com a Qualidade e o Valor Percebido da Informação. Dissertação de Mestrado (Mestrado em Gestão de Informação). Faculdade NOVA de Lisboa, Lisboa - Portugal, 2017.

KANTAR MEDIA. As Tendências das Mídias Sociais para 2019. Inteligência para um Mundo Conectado, 57 p., 2019. Disponível em: < https://www.kantaribopemedia.com/wp-content/uploads/2019/02/AsTend\%C3\%AAncias-das-M\%C3\%ADdias-Sociais-para-2019_pt-BR.pdf > Acesso em nov 2019.

KOTLER, P; KELLER, K. Administração de Marketing. São Paulo: Pearson, 2012.

KUMAR, V., GUPTA, S. Conceptualizing the evolution and future of advertising. Journal of Advertising, v. 45 , n. 3, 2016, p. 302-317.

MACÊDO, I. O Instagram como ferramenta de consumo de moda: Uma análise do papel das líderes de opinião para o comportamento de compra das adolescentes. Dissertação de Mestrado (Administração). Universidade Federal de Pernambuco, Recife, 2016.

MAIA, T; MENEZES, B; FARIAS, F; GOMES, D. O uso do Instagram como Ferramenta de Marketing: Um estudo de caso em empresas do ramo de moda. FACEF Pesquisa, V. 21, N. 1, 2018.

OLIVEIRA, D. Marketing Digital: O uso do Instagram como ferramenta de marketing e prospecção de novos clientes. Trabalho de Conclusão de Curso (Graduação). Universidade Federal da Paraíba, Campina Grande PB, 2018.

ROCK CONTENT. Instagram. Disponível em: < https:/ / rockcontent.com/blog/instagram/> Acesso em 06 de outubro de 2019.

RYAN, D.; JONES, C. Understanding digital marketing: Marketing strategies for engaging in digital generation. Londres: Kogan Page, 2009.

SANTOS, R. A influência do Instagram na atitude do consumidor: O caso da Levi Strauss \& Co. Dissertação de Mestrado. Universidade Europeia, Lisboa, 2016. 
SEBRAE. Instagram para empresas: 10 dicas para promover seu negócio. Disponível em: <http://www.sebrae.com.br/sites/PortalSebrae/ufs/al/artigos/10-dicas-para-promover-o-seu-negocio-noinstagram,e11da535c0597510VgnVCM1000004c00210aRCRD> Acesso em 30 de agosto de 2019.

SILVA, J. Estratégias comunicacionais no Instagram: Um estudo de caso sobre práticas dos influencers portugueses. Dissertação de Mestrado (Comunicação, Cultura e Tecnologias da Informação). Instituto Universitário de Lisboa, Lisboa, 2017.

TORRES, C. A Bíblia do Marketing Digital. São Paulo: Novatec, 2009.

YIN, R. K. Estudo de caso: planejamento e métodos. 2 ed. Porto Alegre: Bookman, 2001. 